\title{
Charcot joint in a case of syringomyelia with spinal dysraphism
}

\author{
Ashwini Sankhe, Ankita Shah 지, Sneha Deshpande, Radhika Kshirsagar
}

Radiology, LTMMC \& GH, Mumbai, India

\section{Correspondence to} Dr Ankita Shah; ankitashah1991@gmail.com

Accepted 17 January 2021

\section{DESCRIPTION}

A 35-year-old man with a swelling over the right shoulder and right anterior chest wall was referred to our hospital. The swelling had been present for over 2 months and was mildly painful. No history of trauma was present. On examination, there was limitation of shoulder movements. Swelling was firm in consistency, non-tender, warm on palpation, fixed to underlying muscles and with reduced sensation. There was no significant history of diabetes mellitus. No prior investigation had been done.

Shoulder radiograph revealed joint destruction and extensive bone resorption of the head of the right humerus with increased shoulder joint space. Also noted was sclerosis of the proximal right humerus and glenoid cavity. Multiple areas of periarticular soft tissue calcifications were seen around the right shoulder joint with displaced adjacent fat planes (figure 1).

CT of the chest was done, which was suggestive of a large, thick-walled peripherally enhancing collection in the region of the right shoulder joint and right anterior and lateral chest wall with multiple osseous fragments/loose bodies within and multiple air foci (figure 2). There was complete resorption of the head and neck of the right humerus, glenoid fossa and lateral aspect of acromion process as well as the coracoid process

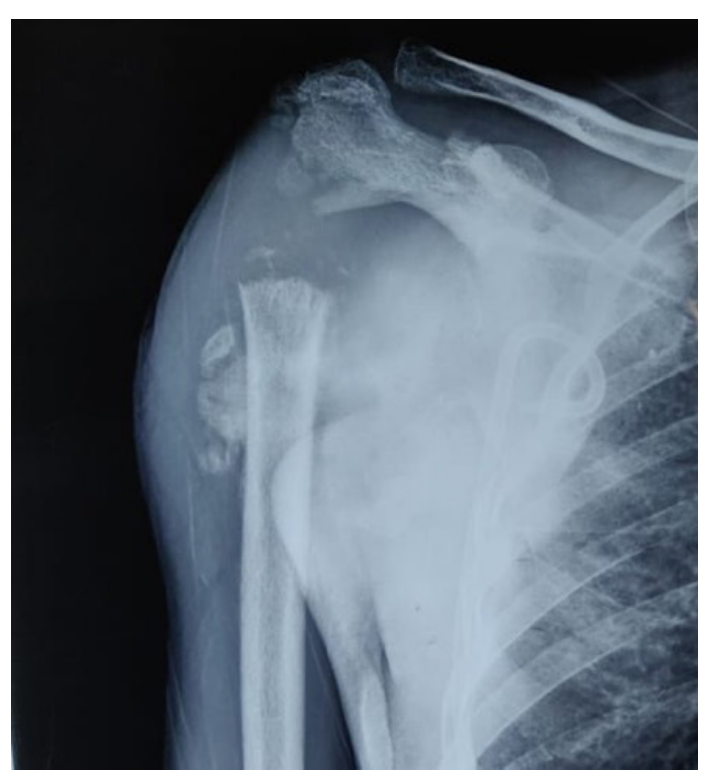

Figure 1 Radiograph of the right shoulder shows resorption of the head of humerus and glenoid cavity with bony fragments around the joint. There is a soft tissue swelling seen surrounding the shoulder joint.
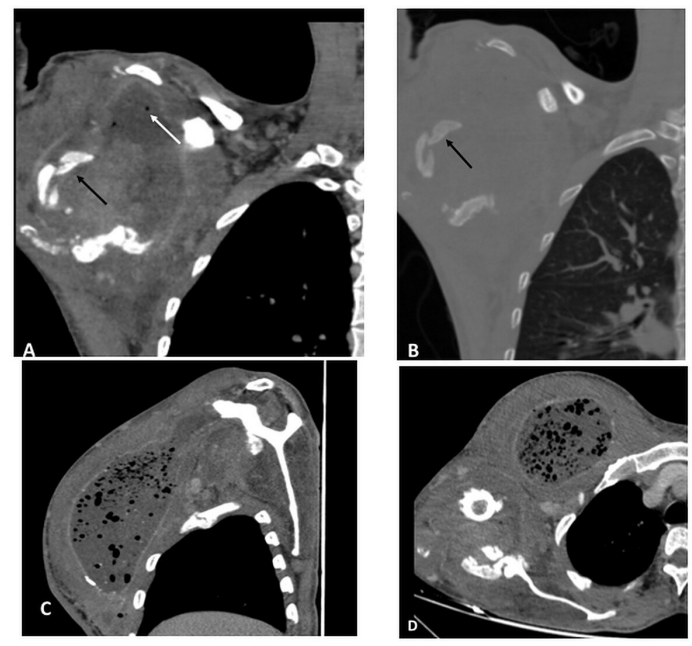

Figure 2 Coronal CT of the right shoulder in soft tissue window $(A)$ and bone window $(B)$ shows a peripherally enhancing collection in the right shoulder joint with loss of joint morphology and multiple osseous fragments (black arrow in $A$ and $B$ ) within with few air foci (white arrow in A). CT of the chest in sagittal (C) and axial (D) reformats shows collection in the right anterior chest wall with multiple air foci within involving the right pectoralis muscles with periosteal reaction along the right scapula and shaft of right humerus.

with resultant disorganisation and dislocation of the right shoulder joint. Radiological features were suggestive of neuropathic joint. In view of presence of air foci, possibility of infection was suggested. A spine MRI was further advised to look for syrinx.

MRI showed bony destruction involving the humeral head and glenoid with complete tear of the tendons of the rotator cuff. Also seen was destruction of the glenoid labrum, glenohumeral ligaments and biceps-labral anchor. A large, thick-walled peripherally enhancing collection with patchy areas of diffusion restriction was seen with extension into the acromioclavicular joint superiorly and into the right arm into biceps muscles and posterior compartment of the right arm (figure 3).

MRI of the whole spine showed a low-lying cord with syrinx from C1 to L3 vertebral level. Diastematomyelia of the terminal portion of the spinal cord at L3 level was noted. Anterior meningocele was seen from S3 vertebral level to the coccyx causing scalloping of the posterior cortex of the vertebral bodies with spina bifida from S2 to S5 vertebral levels (figure 3). 
The patient was treated conservatively with antiinflammatory drugs and antibiotics for infection. He was advised protective motion exercises and a sling.
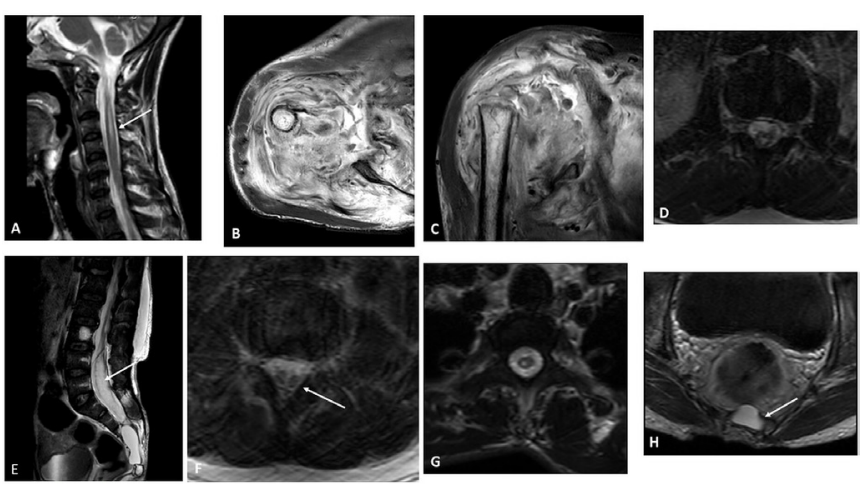

Figure 3 Sagittal T2-weighted images of the cervicothoracic (A) and lumbosacral (E) spine show syrinx within the spinal cord (white arrow in A) axial stir (B) and coronal stir (C). MRls show resorption of the right humeral head and glenoid and collection in the right shoulder joint and proximal right arm. Complete tear of the tendons of the rotator cuff muscles and destruction of the glenoid labrum, glenohumeral ligaments and biceps-labral anchor is seen. T2-weighted images of the spine show focal splitting of the terminal portion of the spinal cord at L3 level suggesting diastematomyelia (white arrow in F). A CSF-filled sac is noted in the spinal canal suggesting a meningocele (arrow in $\mathrm{E}$ and $\mathrm{H}$ ). Spina bifida is noted in the sacral vertebrae. CSF, Cerebrospinal Fluid.

\section{Learning points}

- Neuropathic osteoarthropathy is described as the osseous and joint changes that occur secondary to loss of sensation, accompanying a variety of disorders. Location of the bony and joint findings, age of the patient and clinical history may provide clues to the underlying disease. ${ }^{1}$

- The six Ds of neuropathic joint include distension of joint, increased density, debris, destruction of articular surface, dislocation and disorganisation of joint.

- In syringomyelia, neuropathic changes are relatively common in the shoulder and elbow. ${ }^{2}$

Contributors $A S$ and RK-writing the manuscript with data collection. AS and SD-reviewing the manuscript.

Funding The authors have not declared a specific grant for this research from any funding agency in the public, commercial or not-for-profit sectors.

Competing interests None declared.

Patient consent for publication Obtained.

Provenance and peer review Not commissioned; externally peer reviewed.

\section{ORCID iD}

Ankita Shah http://orcid.org/0000-0002-1900-2554

\section{REFERENCES}

1 Jones EA, Manaster BJ, May DA, et al. Neuropathic osteoarthropathy: diagnostic dilemmas and differential diagnosis. Radiographics 2000;20:S279-93.

2 Nacir B, Arslan Cebeci S, Cetinkaya E, et al. Neuropathic arthropathy progressing with multiple joint involvement in the upper extremity due to syringomyelia and type I Arnold-Chiari malformation. Rheumatol Int 2010;30:979-83.

Copyright 2021 BMJ Publishing Group. All rights reserved. For permission to reuse any of this content visit

https://www.bmj.com/company/products-services/rights-and-licensing/permissions/

BMJ Case Report Fellows may re-use this article for personal use and teaching without any further permission.

Become a Fellow of BMJ Case Reports today and you can:

- Submit as many cases as you like

- Enjoy fast sympathetic peer review and rapid publication of accepted articles

- Access all the published articles

Re-use any of the published material for personal use and teaching without further permission

Customer Service

If you have any further queries about your subscription, please contact our customer services team on +44 (0) 2071111105 or via email at support@bmj.com.

Visit casereports.bmj.com for more articles like this and to become a Fellow 